\title{
QUASI-PERIODIC SOLUTIONS OF FRACTIONAL NABLA DIFFERENCE SYSTEMS
}

\author{
JAGAN MOHAn JONNALAGADDA
}

Abstract. In this paper, we analyse periodic properties of fractional nabla difference systems. First, we prove that a system of fractional nabla difference equations with a periodic right hand side can not possess a periodic solution. Next, we establish sufficient conditions on the existence of a unique $S$-asymptotically $T$-periodic solution for this difference system. Finally, we provide an example illustrating the obtained results.

Mathematics subject classification (2010): 34A08, 39A23, 39A99.

Keywords and phrases: Fractional order, backward (nabla) difference, fixed point, existence, uniqueness, periodic.

\section{REFERENCES}

[1] Christopher Goodrich and Allan C. Peterson, Discrete Fractional Calculus, Springer International Publishing, 2015, doi: 10.1007/978-3-319-25562-0.

[2] J. Diblik, M. FECKAN AND M. Pospisil, Nonexistence of periodic solutions and S-asymptotically periodic solutions in fractional difference equations, Applied Mathematics and Computation 257 (2015), 230-240.

[3] Eva Kaslik And Seenith Sivasundaram, Nonexistence of periodic solutions in fractional order dynamical systems and a remarkable difference between integer and fractional order derivatives of periodic functions, Nonlinear Analysis: Real World Applications 13 (2012), 1489-1497.

[4] Ferhan M. Atici and Paul W. Eloe, Linear systems of nabla fractional difference equations, Rocky Mountain Journal of Mathematics 41, 2 (2011), 353-370.

[5] Ivan Area, Jorge Losada and Juan J. Nieto, On fractional derivatives and primitives of periodic functions, Abstract and Applied Analysis 2014, Article ID 392598, 8 Pages, doi: $10.1155 / 2014 / 392598$.

[6] IVAn ARea, Jorge Losada And Juan J. Nieto, On quasi-periodicity properties of fractional integrals and fractional derivatives of periodic functions, Integral Transforms and Special Functions, doi: 10.1080/10652469.2015.1087400.

[7] IVAN AREA, JoRge Los ADA AND JUAN J. Nieto, On quasi-periodic properties of fractional sums and fractional differences of periodic functions, Applied Mathematics and Computation 273 (2016), 190-200.

[8] Jaganmohan Jonnalagadda, Solutions of fractional nabla difference equations - existence \& uniqueness, Opuscula Mathematica 36, 2 (2016), 215-238.

[9] JAGANMOHAN JONNALAGADDA, Analysis of a system of nonlinear fractional nabla difference equations, Int. J. Dynamical Systems and Differential Equations 5, 2 (2015), 149-174.

[10] Jaganmohan Jonnalagadda, Periodic solutions of fractional nabla difference equations, Communications in Applied Analysis 20 (2016), 585-609.

[11] J. Jagan Mohan And G. V. S. R. Deekshitulu, Solutions of nabla fractional difference equations using $N$-transforms, Commun. Math. Stat. 2 (2014), 1-16.

[12] JAN ČERMÁK, TOMÁš Kisela AND LudĚK NeChVÁtAL, Stability and asymptotic properties of a linear fractional difference equation, Advances in Difference Equations 2012 (2012), 122.

[13] JAN ČERMÁK, IstV́an GyôRI AND LudĚK NechVÁtal, Stability regions for linear fractional difference systems and their discretizations, Applied Mathematics and Computation 219 (2013), 7012 7022. 
[14] Jin Rong Wang, Michal Feckan And Yong Zhou, Nonexistence of periodic solutions and asymptotically periodic solutions for fractional differential equations, Commun. Nonlinear Sci. Numer. Simulat. 18 (2013), 246-256.

[15] K. S. Miller AND B. Ross, Fractional difference calculus, Proceedings of the International Symposium on Univalent Functions, Fractional Calculus and Their Applications, 139-152, Nihon University, Koriyama, Japan, 1989.

[16] A. A. Kilbas, H. M. Srivastava and J. J. Trujillo, Theory and Applications of Fractional Differential Equations, North-Holland Mathematics Studies, Elsevier Science B. V., Amsterdam, The Netherlands, 2006.

[17] E. Kreyszig, Introductory Functional Analysis with Applications, John Wiley and Sons, Canada, 1978.

[18] Mohammad Saleh Tavazoei, A note on fractional order derivatives of periodic functions, Automatica 46 (2010), 945-948.

[19] Mohammad Saleh Tavazoei and Mohammad Haeri, A proof for non existence of periodic solutions in time invariant fractional order systems, Automatica 45 (2009), 1886-1890.

[20] Nihan ACAR And Ferhan M. ATICI, Exponential functions of discrete fractional calculus, Appl. Anal. Discrete Math. 7 (2013), 343-353.

[21] E. OMeY, Asymptotic properties of convolution products of sequences, Publications De L'Institut Mathematique, Nouvelle Serie 36, 50 (1986), 67-78.

[22] I. Podlubny, Fractional Differential Equations, Academic Press, San Diego, 1999. 